\title{
Future plans of final-year dental therapy students at Sefako Makgatho Health
} Sciences University

SADJ November 2021, Vol. 76 No. 10 p587 - p592

\author{
MM Masetla', SR Mthethwa²
}

\begin{abstract}
Introduction

The distribution and accessibility of healthcare professionals as well as the quality of healthcare services that the healthcare system is able to deliver are significantly affected by the choices of the medical and other health science graduates.
\end{abstract}

\section{Aims and objectives}

To describe the career and practice intentions of final-year dental therapy students' classes of the years 2017 and 2018 at Sefako Makgatho Health Sciences University

\section{Design}

A cross-sectional survey.

\section{Methods}

A structured, closed, self-administered, questionnaire was used to collect data. Data related to demographic characteristics, work preferences and career intentions were acquired and then captured in Microsoft excel software.

\section{Results}

Female students constituted the majority (54.05\%). The average age of the population was 23 years old. $64.86 \%$ of the students preferred to work in the public sector. A little more (18.9\% vs $13.5 \%)$ students had been offered jobs than had applied. Twice as many $(54.05 \%$ vs. $27.03 \%)$ preferred to work in the Gauteng province as the percentage who resided there. No fewer than $59.46 \%$ saw themselves owning private practices in five years' time.

\section{Author affiliations:}

1. Ms Modjadji Mary Masetla: BDT, MPH. Sefako Makgatho Health Sciences University, South Africa. ORCID Number: 0000-0003-21623429

2. Sibusiso Rockfort Mthethwa: $B D S, M P H, P h D$. Sefako Makgatho Health Sciences University. ORCID Number: 0000-0003-0420-808X

\section{Corresponding author:}

Dr SR Mthethwa: Medunsa Campus, PO Box D24, Sefako Makgatho Health Sciences University 0204

Tel: 0125215888 / Fax: 0125124274

Email: rocky.mthethwa@smu.ac.za

\section{Author contributions:}

1. Modjadji Mary Masetla: Conception; design; acquisition of data - $50 \%$

2. Sibusiso R Mthethwa: Conception; design; acquisition of data; analysis and interpretation of data; drafting the article - $50 \%$

\section{Conclusion}

The majority of students preferred to work in the public sector after graduating with the intention of owning a private practice in the medium term.

\section{INTRODUCTION AND BACKGROUND}

The distribution and accessibility of healthcare professionals as well as the quality of healthcare services that the healthcare system is able to deliver are significantly affected by the choices of the medical and other health science graduates. ${ }^{1}$ There is severe shortage and maldistribution of oral health personnel in South Africa. The size of the oral health personnel, which includes dental assistants, oral hygienists, dental therapists, and dentists, has been estimated to be 0.2 per 1000 population. ${ }^{2}$ An overwhelming majority of oral health professionals work in the private sector. ${ }^{3}$ There is an imbalance in the geographic distribution of oral health personnel favouring large urban areas. ${ }^{3,4}$ There are several possible explanations for the maldistribution of dental therapists. Chief among them is the lack of posts and poor salaries in the public sector. ${ }^{5}$ Others include the lack of academic growth (career pathing). ${ }^{6}$ These factors may account for the high attrition experienced in the profession of dental therapy. A number of studies have found that a significant proportion of dental therapists go on to pursue other careers or study dentistry. ${ }^{7,8}$ These findings are rather unfortunate since the profession of dental therapy has long been held up as a model for reducing access to care barriers in high-risk underserved populations worldwide. - $^{9-11}$ The structural ills of the health system which necessitated the founding of the dental therapy profession in South Africa have not been adequately corrected. These consists of, among others, a shortage and inequitable distribution of oral health personnel, ${ }^{3,12-14}$ lack of dental services at primary health care level, ${ }^{15}$ high attendance rates where services were available and accessible, ${ }^{16,18}$ and limited range of services offered. ${ }^{18}$

In South Africa, dental therapy training is currently offered at the dental schools of the universities of KwaZulu-Natal and Sefako Makgatho Health Sciences University. The combined overall mean number of dental therapy graduates produced annually is a little less than thirty. ${ }^{8,19} \mathrm{~A}$ meagre dental therapist to population ratio of 0.13 per 10,000 has been estimated. ${ }^{20}$ The low numbers of dental therapist in training coupled with the maldistribution of professionals militate against the profession's capability for reducing access to care barriers. 
The urgent need to train a great many dental therapists to alleviate the shortage of oral health personnel has long been recognised. ${ }^{21}$ The human resource plan of the National Department of Health envisaged an increased annual output of 600 dental therapists from a baseline of $25 . .^{22}$ An argument has recently been made that we should be training fewer dentists and more oral hygienists and dental therapists. ${ }^{5}$ This line of reasoning is supported by evidence emerging from epidemiological studies of disease burden.

Evidence indicates that dental caries is the most prevalent oral disease ${ }^{23}$ - the latest national survey found that more than $80 \%$ of dental caries in children was untreated. ${ }^{24}$ New oral health priorities, which include conditions such as periodontal disease, oral manifestations of HIV/AIDS, dental trauma, oral cancer and craniofacial anomalies, have arisen. ${ }^{25,26}$ The imbalance in the geographic distribution of oral health personnel warrants a survey of the future plans of dental therapy graduates. The current study, which was part of a larger study which examined trends in enrolments, examination pass rate and graduations of dental therapy student cohorts at Sefako Makgatho Health Science University during the period 2004 to $2014,{ }^{19}$ describes future plans of the 2017 and 2018 cohorts of dental therapy students in the final year of study.

\section{OBJECTIVE OF THE STUDY}

To describe the demographic characteristics, work preferences and career intentions of final-year dental therapy students'

\begin{tabular}{|c|c|c|c|c|c|c|}
\hline Age in years & 2017 class & & & 2018 class & & \\
\hline & Female n (\%) & Male n (\%) & Total n (\%) & Female n (\%) & Male $\mathrm{n}(\%)$ & Total n (\%) \\
\hline 20 & $2(25)$ & $0(0)$ & $2(12.5)$ & $5(41.67)$ & $1(11.11)$ & $6(28.57)$ \\
\hline 21 & $1(12.5)$ & $1(12.5)$ & $2(12.5)$ & $3(25)$ & $2(22.22)$ & 5 (23.81) \\
\hline 22 & $3(37.5)$ & $2(25)$ & $5(31.25)$ & $0(0)$ & $1(11.11)$ & $1(4.76)$ \\
\hline 23 & $1(12.5)$ & $1(12.5)$ & $2(12.5)$ & 1 (8.33) & $2(22.22)$ & $3(14.29)$ \\
\hline 24 & $0(0)$ & $0(0)$ & $0(0)$ & $2(16.67)$ & $1(11.11)$ & $3(14.29)$ \\
\hline 25 & $1(12.5)$ & $2(25)$ & $3(18.75)$ & $1(8.33)$ & $0(0)$ & $1(4.76)$ \\
\hline 26 & $0(0)$ & 1 (12.5) & $1(6.25)$ & $0(0)$ & $0(0)$ & $0(0)$ \\
\hline 27 & $0(0)$ & $0(0)$ & $0(0)$ & $0(0)$ & $1(11.11)$ & $1(4.76)$ \\
\hline 29 & $0(0)$ & $1(12.5)$ & $1(6.25)$ & $0(0)$ & $\mathrm{O}(0)$ & $0(0)$ \\
\hline 30 & $0(0)$ & $0(0)$ & $0(0)$ & $O(0)$ & $1(11.11)$ & $1(4.76)$ \\
\hline Total n (\%) & 8 (100) & 8 (100) & $16(100)$ & 12 (100) & $9(100)$ & 21 (100) \\
\hline
\end{tabular}

The total number of students in the 2018 class was $23.8 \%$ higher than that in the 2017 class. The average age and standard deviation of the classes were similar [ 23 years SD $=2.422$ (2017) vs. 22.38 years SD = 2.636 (2018)] Gender parity was observed in the 2017 class. In contrast, female students constituted the majority $(57.14 \%)$ in the 2018 class.

Table 2: Person or institution responsible for paying study fees

\begin{tabular}{|c|c|c|c|c|c|c|}
\hline \multirow[t]{2}{*}{ Cohorts } & \multicolumn{6}{|c|}{ Person or institution responsible for paying study fees } \\
\hline & DOH n (\%) & NSFAS n (\%) & Other $n(\%)$ & Parents n (\%) & Self $n(\%)$ & Total $\mathrm{n}(\%)$ \\
\hline 2017 & $4(66.66)$ & $5(25)$ & $1(50)$ & $4(57.14)$ & $2(100)$ & $16(43.24)$ \\
\hline 2018 & $2(33.33)$ & $15(75)$ & $1(50)$ & $3(42.86)$ & $0(0)$ & $21(56.76)$ \\
\hline Total n (\%) & $6(100)$ & $20(100)$ & $2(100)$ & $7(100)$ & $2(100)$ & $37(100)$ \\
\hline
\end{tabular}

DOH - Department of Health; NSFAS - National Student Financial Aid Scheme

DOH - Department of Health; NSFAS - National Student Financial Aid Scheme

An equal (25\%) proportion of students in the 2017 class had their study fees paid either by the Health Department or their parents. None of the students in the 2018 class were personally responsible for paying their fees. In fact, the National Student Financial Aid Scheme (NSFAS) paid the fees for $71.43 \%$ of them.

\begin{tabular}{|c|c|c|c|}
\hline Province & 2017 class $n(\%)$ & 2018 class $n(\%)$ & Total n (\%) \\
\hline Eastern Cape & $1(6.25)$ & $0(0)$ & $1(2.7)$ \\
\hline Gauteng & $5(31.25)$ & $5(23.81)$ & $10(27.03)$ \\
\hline KZN & $2(12.5)$ & 2 (9.52) & $4(10.81)$ \\
\hline Limpopo & $6(37.5)$ & $10(47.62)$ & $16(43.24)$ \\
\hline Mpumalanga & $1(6.25)$ & $4(19.05)$ & $5(13.51)$ \\
\hline North West & $1(6.25)$ & $0(0)$ & $1(2.7)$ \\
\hline Total n (\%) & $16(100)$ & $21(100)$ & $37(100)$ \\
\hline
\end{tabular}




\begin{tabular}{|c|c|c|c|}
\hline Preferred province & 2017 class $n(\%)$ & 2018 class $n(\%)$ & Total n (\%) \\
\hline Any province & $0(0)$ & $2(9.52)$ & $2(5.41)$ \\
\hline Gauteng & $11(68.75)$ & $9(42.86)$ & $20(54.05)$ \\
\hline KZN/ Gauteng & $1(6.25)$ & $0(0)$ & $1(2.7)$ \\
\hline Limpopo & $2(12.5)$ & $4(19.05)$ & $6(16.22)$ \\
\hline Limpopo/Gauteng & $0(0)$ & $1(4.76)$ & $1(2.7)$ \\
\hline Mpumalanga & $1(6.25)$ & $4(19.05)$ & $5(13.51)$ \\
\hline Mpumalanga/Gauteng & $0(0)$ & $1(4.76)$ & $1(2.7)$ \\
\hline North West & $1(6.25)$ & $0(0)$ & $1(2.7)$ \\
\hline Total n (\%) & $16(100)$ & $21(56.8)$ & $37(100)$ \\
\hline
\end{tabular}

\begin{tabular}{|c|c|c|c|}
\hline Job sector & 2017 class $n(\%)$ & 2018 class $n(\%)$ & Total n (\%) \\
\hline Don't know & $0(0)$ & $3(14.29)$ & $3(8.11)$ \\
\hline Private practice & $4(25)$ & $3(14.29)$ & $7(18.91)$ \\
\hline Public sector or Private practice & $1(6.25)$ & $1(4.76)$ & $2(5.41)$ \\
\hline Public sector & $11(68.75)$ & $13(61.9)$ & $24(64.86)$ \\
\hline University & $0(0)$ & $1(4.76)$ & $1(2.7)$ \\
\hline Total n (\%) & $16(100)$ & $21(100)$ & $37(100)$ \\
\hline
\end{tabular}

\begin{tabular}{|c|c|c|c|}
\hline Applied for a job & 2017 class $n(\%)$ & 2018 class $n(\%)$ & Total n (\%) \\
\hline No & $11(68.75)$ & $21(100)$ & $32(86.5)$ \\
\hline Yes & $5(31.25)$ & $0(0)$ & 5 (13.5) \\
\hline Total n (\%) & $16(100)$ & $21(100)$ & $37(100)$ \\
\hline
\end{tabular}

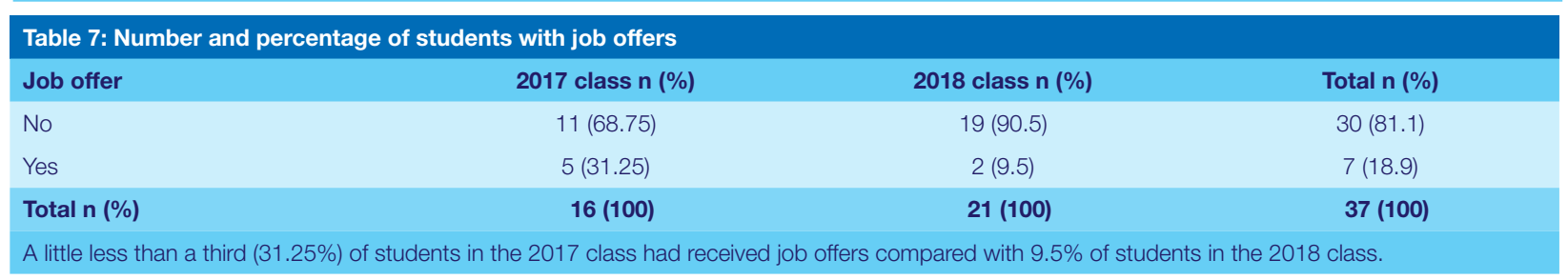

classes of the years 2017 and 2018 at Sefako Makgatho Health Sciences University.

\section{MATERIALS AND METHODS \\ Design}

This was a cross-sectional survey.

\section{Target population}

The study population consisted of final-year classes of dental therapy student enrolled at Sefako Makgatho Health Sciences University between the years 2017 and 2018.

\section{Study sample}

Only students who provided informed consent were enrolled as it turned out, all students were recruited.

\section{MEASUREMENTS}

Questionnaire

A structured, closed, self-administered, questionnaire was used to collect data. Data related to demographic characteristics and career and practice intentions were acquired and then captured in Microsoft excel software.

\section{Ethical considerations}

Ethical approval for the study was granted by the Ethics Committee of the Sefako Makgatho Health Sciences University (SMREC/D/1820/2017). Permission to conduct the study was granted by the Chief Executive Officer (CEO) of Medunsa Oral health Centre.

\section{STATISTICAL ANALYSIS}

Data was captured, coded and cleaned in Microsoft excel software and then transferred to Statistical Package for the Social Sciences (SPSS) software for analysis. Means, frequencies and proportions (percentages) were calculated.

\section{RESULTS}

Data of a population of 37 dental therapy students was analysed. A response rate of $100 \%$ was achieved. No fewer than $59.46 \%$ of the population saw themselves 
Table 8: Number and percentage of students intending to study dentistry

\begin{tabular}{lccc} 
Intend to study dentistry & $\mathbf{2 0 1 7}$ class $\mathbf{n}(\%)$ & $\mathbf{2 0 1 8}$ class $\mathbf{n}(\%)$ & Total $\mathbf{n}(\%)$ \\
\hline No & $12(75)$ & $17(81)$ & $29(78.3)$ \\
Yes & $4(25)$ & $4(19)$ & $8(21.6)$ \\
\hline Total $\mathbf{n}(\%)$ & $\mathbf{1 6}(\mathbf{4 3 . 2})$ & $\mathbf{2 1 ( 5 6 . 8 )}$ & $\mathbf{3 7}(\mathbf{1 0 0})$ \\
\hline
\end{tabular}

\begin{tabular}{|c|c|c|c|}
\hline Career intentions & 2017 class $n(\%)$ & 2018 class n (\%) & Total n (\%) \\
\hline No medium term plans & 0 & $1(4.76)$ & $1(2.7)$ \\
\hline Own a practice & $9(56.25)$ & $13(61.9)$ & $22(59.46)$ \\
\hline $\begin{array}{l}\text { Undecided between owning a } \\
\text { practice and pursuing postgraduate } \\
\text { studies }\end{array}$ & $1(6.25)$ & $2(9.52)$ & $3(8.11)$ \\
\hline Pursue postgraduate studies & $2(12.5)$ & $2(9.52)$ & $4(10.81)$ \\
\hline Study dentistry & $2(12.5)$ & $1(4.76)$ & $3(8.11)$ \\
\hline Study medicine & 0 & $1(4.76)$ & $1(2.7)$ \\
\hline Study pharmacy & $1(6.25)$ & 0 & $1(2.7)$ \\
\hline Work in the public sector & $1(6.25)$ & $1(4.76)$ & $2(5.41)$ \\
\hline Total n (\%) & $16(100)$ & $21(100)$ & $37(100)$ \\
\hline
\end{tabular}

owning private practices in stark contrast to $5.41 \%$ who saw themselves working in the public sector in five years' time. A handful (13.51\%) of students saw themselves changing careers and studying either dentistry, medicine or pharmacy.

\section{DISCUSSION}

This study set out to survey the future plans of final-year dental therapy students' classes of the years 2017 and 2018 at Sefako Makgatho Health Sciences University. A response rate of $100 \%$ was obtained.

\section{Demographic characteristics}

The size of the student population in the current study was 37 i.e. 16 and 21 students in the 2017 and 2018 classes respectively (Table 1). These somewhat improved results differ from those of an earlier study by Masetla and Mthethwa (2018) who found that the median number of third year enrolees during the decade between 2004 and 2014 was 13 with an interquartile range of 9 to $15 .^{19}$

The results of this study indicate that female students constituted the majority (54.05\%) (Table 1). The present findings seem to be consistent with other research which found that female students constitute the majority of dental therapy students. ${ }^{8,19}$

The current study found that the average age of the students was 23 years old (Table 1). This finding does not support the previous research. The analysis of a decadelong (2001 to 2010) data of dental therapy students' enrolment at the University of KwaZulu-Natal by Singh and Combrinck found that all students on entrance were under 20 years of age. ${ }^{8}$

Person or institution responsible for paying study fees

The results of this study show a significant increase (31.25\% vs $71.43 \%)$ in the proportion of students who relied on NSFAS to pay for theirs studies between the years
2017 and 2018 (Table 2). This finding was unexpected, considering the fact free higher education for new first year students from families that earn less than R350 000 per year was only introduced in 2018.27

\section{Province of residence}

The results of this study show that the bulk $(70.27 \%)$ of students came from the provinces of Limpopo and Gauteng (Table 3). The province of Limpopo was overrepresented in the student population of the current study. The province of Gauteng, the home province of Sefako Makgatho Health Sciences University, shares borders with the provinces of Mpumalanga, Limpopo and North West.

Preferred province for work

The most interesting finding was that twice as many (54.05\% vs. $27.03 \%$ ) students preferred to live and work in the Gauteng province as the percentage who resided there (Tables 3 and 4). The present findings seem to be consistent with other research which found that dental care professionals are concentrated in urban areas. ${ }^{3,4}$ Gauteng is the most urbanised province in South Africa $-94 \%$ of the population lives in urban areas. ${ }^{28}$

Another important finding was that a little more than a third (37.5\%) of students from Limpopo preferred to work in Limpopo (Tables 3 and 4). These results differ from those of Naidu and Diab (2013) who found that health science students of rural origin were significantly more likely to prefer working a rural area than their urban-origin counterparts. ${ }^{1}$ Limpopo has the highest rural profile of all provinces in South Africa. It is unfortunate that students were not asked to classify their homes as being situated in an urban or rural area in the current study.

It would seem that the area of location of the training institution has an influence on the choice of area of practice of the graduates. These findings are rather disappointing as they suggest that redressing the rural- 
urban dentist-patient ratio imbalance in South Africa will remain a pipedream.

\section{Preferred job sector}

It is interesting to note that a little less than two-thirds (64.86\%) of the students preferred to work in the public sector (Table 5). These results do not support the previous research. Singh and Combrinck (2011) found that the percentage of graduates over the period from 2001 to 2010 from the University of KwaZulu-Natal in the public sector showed a steady decrease from a maximum of $35 \%$ in 1985 to $10 \%$ in 2000. From 2000 onwards this percentage stayed more or less the same, fluctuating around a mean of $9.5 \% .^{8}$ These findings suggest that the students are either altruistic or are undeterred by the challenges prevailing in the public sector. Poor job satisfaction among dental therapists in the public sector has been reported. ${ }^{29}$ Several possible explanations for the dissatisfaction have been put forward. These include among others the lack of posts, lack of status and promotion potential, poorly functioning dental facilities, and inadequate remuneration. .,29 $^{5}$

Comparison of the percentage of students who had received job offers with those who had applied

The results of this study indicate that a little more $18.9 \%$ vs $13.5 \%$ ) students had been offered jobs than had applied (Tables 6 and 7). It is not unreasonable to assume that the students who had received job offers were the one and the same as those who had received financial assistance for their studies from the department of health - the health department was liable for the payment of university fees for $16.2 \%$ of students. The low percentage of students with job offers is very concerning for the reason that data for the current study was collected towards the end of the second semester.

Number and percentage of students intending to study dentistry

The results of this study indicate that one out of five students intended to study dentistry (Table 8). These findings are consistent with those of Singh and Combrinck (2011) who found that the percentage of the University of KwaZuluNatal graduates who went on to study dentistry showed a steady decrease up to 1993. From 1993 onwards it stayed more or less the same, fluctuating around a mean of 19\%. ${ }^{8}$ The decline in 1992 coincided with the introduction of private practice for dental therapists. ${ }^{30}$ The findings of the current study confirm the widely held belief that many dental therapists chose this profession as a stepping stone to dentistry. The assertion by the former dean of the two dental schools training therapists cited in the study by Singh (2014) that almost one-third of the first-year dentistry class of 2009 were qualified dental therapists lends further support to this belief. ${ }^{29}$ The former dean must have been referring to the University of Limpopo (Medunsa Campus), the predecessor of Sefako Makgatho Health Sciences University, since the University of KwaZuluNatal does not train dentists. The findings of the current study must however be interpreted with caution since the practice patterns of graduates of Sefako Makgatho Health Sciences University and its predecessor institutions have not previously been described.

The most interesting finding was that the responses of students to the question about their intentions to study dentistry contrasted sharply with their responses to the question about where they saw themselves in five years' time. One out of five students intended to study dentistry compared with $8 \%$ who saw themselves studying dentistry in five years' time (Tables 8 and 9). It is difficult to explain these rather contradictory results.

\section{Medium term career intentions}

It is interesting to note that $59.46 \%$ of the students saw themselves owning private practices in stark contrast to the $5.41 \%$ who saw themselves working in the public sector in five years' time (Tables 9). This combination of findings, though somewhat higher for those who saw themselves owning private practices in the current study, is consistent with those of Singh and Combrinck (2011) who found that the percentage of University of KwaZulu-Natal graduates in private practice between the years 1994 and 2010 has fluctuated around a mean of $47 \%$. Furthermore, they found that the percentage of students in the public sector has fluctuated around a mean of 9.5\% between the years 2000 and $201 .{ }^{8}$ The results of the current study were not very encouraging. The very low percentage $(5.41 \%)$ of students who saw themselves working in the public sector in five years' time is extremely concerning. It suggests that until such time that dental therapists sense that the widely publicized shortcomings of the public service have been addressed, the high turnover rate experienced in the public service sector will continue. Seeing that $59.46 \%$ of the students saw themselves working in the public sector in five years' time, it would be interesting to find out if they were aware of the challenges of private practice. The frustrations experienced by dental therapists with their limited scope in private practice have been documented. Singh (2014) concluded that the roles and scope of all members of the oral health team needs to be redefined within the context of the primary health care approach. ${ }^{29}$

The results of this study show that students have varied career aspirations. The motivation for choosing dental therapy as a career is an important issue for future research.

\section{Limitations of the study}

The potential threat to the internal validity of the study was that arising from the challenge of coding the responses to the open-ended question - where do you see yourself in five years?

\section{CONCLUSION}

The majority of students preferred to work in the public sector after graduating with the intention of owning a private practice in the medium term.

\section{References}

1. Naidu C, Irlam J, Diab PN. Career and practice intentions of health science students at three South African health science faculties Journal of African. Afr $\mathrm{J}$ Health Prof Educ 2013; 5(2): 68-71

2. World Health Organization. Dentistry personnel density (per 1000 population) Retrieved fromhttp://data. un.org/Data.aspx? $\mathrm{q}=$ dentistry $\& d=\mathrm{d}=\mathrm{HO} \& \mathrm{f}=\mathrm{MEASUR}$ E_CODE\%3AHRH_28 [Accessed 04/07/2018]

3. Lalloo R. A national human resources plan for oral health: is it feasible? SADJ 2007; 62(8):360-4.

4. van Wyk PJ, Kroon FJ, Cleaton-Jones JPE. Geographical distribution of dental operators in South Africa over the period 1972-1992. J Dent Assoc S Afr 1994; 49:457-62 
5. Bhayat A. \& Chikte U. (2019). Human Resources for Oral Health Care in South Africa: A 2018 Update. Int J Environ Res Public Health 2019; 16(10): 1668

6. Prinsloo P. M. (1994). The wastage/losses/ attrition of dental therapists in South Africa. Oral Hygiene Association of South Africa Journal 1994; 6(1); 4-7

7. Hugo J. Mid-level health workers in South Africa -not an easy option. In: ljumba P, Barron P, editors. South African Health Review. Durban: Health Systems Trust; 2005.p. 148-59

8. Singh P. K. \& Combrink M. (2011). Profile of the dental therapy graduate at the University of KwaZulu-Natal. South African Dental Journal 2011; 66(10): 468,470-4

9. Y. Tony Yang Y, Brian Chen, JD, Tanya Wanchek, JD. Dental Therapists: A Solution to a Shortage of Dentists in Underserved Communities? Public Health Rep. 2017;132(3):285-288

10. Brickle CM, Self KD. Dental Therapists as New Oral Health Practitioners: Increasing Access for Underserved Populations. J Dent Educ. 2017;81(9): eS65-eS72.

11. Uswak G, Keller-Kurysh E. Influence of private practice employment of dental therapists in Saskatchewan on the future supply of dental therapists in Canada. J Dent Educ. 2012;76(8):1092-1101.

12. Van Wyk PJ, Van Wyk C. Caries status and treatment needs in South Africa: report of the 1999-2002 national children's oral health survey. S Afr Dent J 2004; 59:238-42.

13. Department of Health. South African National Oral Health Strategy. Oral Health Directorate, Pretoria, 2005. Retrieved from http://www.doh.gov.za/docs/index.html/

14. Department of Health. A National Human Resources for Health Planning Framework, Pretoria, 2006; 59. Retrieved from http://www.doh.gov.za/docs/index.html/

15. Visser R, Bhana R, Monticelli F. National health care Facilities Baseline Audit, National Summary Report September 2012 Revised February 2013, Health Systems Trust. Available: www.doh.gov.za/docs/reports/2013/ Healthcare.pdf [Accessed 25 September 2013].

16. Bhayat A, Cleaton-Jones P. Dental clinic attendance in Soweto, South Africa, before and after the introduction of free primary dental health services. Community Dent Oral Epidemiol 2003; 31(2): 105-10.

17. Harkinson BN, Cleaton-Jones PE. Analysis of attendance rates at Soweto dental clinics 1995-2002. S Afr Dent J 2004; 59(4): 147-9.

18. Lesolang RR, Motloba DP, Lalloo r. reasons for tooth extraction at the Winterveldt clinic: 1998-2002. S Afr Dent J 2009; 64:214-8.

19. Masetla MM, Mthethwa SR. Dental Therapy Student cohorts: Trends in enrolment and progress at a South African University. SADJ 2018; 73(6):406-10

20. Department of Health. A National Human Resources for Health Planning Framework, Pretoria, 2006; 59. Retrieved from http://www.doh.gov.za/docs/index.html/

21. Rossouw L. Dentists, The Oral Health Team, Their Numbers, Distribution And Income Profiles In South Africa: 1995-2010 AD. Final Memorandum for the Dental Association of South Africa Health Services Committee. 1996

22. Department of Health. HRH Strategy for the Health Sector: 2012/13 - 2016/17 Retrieved from http://www. hst.org.za/publications/NonHST\%20Publications/hrh_ strategy-2.pdf [Accessed 23/11/2017]

23. Department of Health. National Oral Health Survey: South Africa 1988/89. Pretoria: Government Printer; 1994.
24. van Wyk P, van Wyk C. Oral health in South Africa. Int Dent J. 2004;54(6 Suppl 1):373-7.

25. Petersen PE. Priorities for research for oral health in the 21st Century - the approach of the WHO Global Oral Health Programme. Community Dental Health (2005) 22, 71-4

26. Department of Health. South African Oral Health Strategy. Retrieved from www.health.gov.za/.../ strategic.../130-sd2005?...south-african-nationaloral-health-stra. [Accessed 04/07/2018]

27. National Treasury. 2018 Peoples Guide English. Retrieved from http://www.treasury.gov. za/ documents/national\%20budget/2018/ guides/2018\%20 Peoples\%20Guide\%20English.pdf [Accessed 31/07/2020]

28. Statistics South Africa. The population of Gauteng. http://www.statssa.gov.za/publications/LivinglnGP/ LivingInGP.pdf [Accessed 31/07/2020]

29. Singh PK. Job satisfaction among dental therapists in South Africa. Journal of Public Health Dentistry 2014;74(1):28-33

30. Health Professions Council of South Africa. Regulations Defining the Scope of the Profession of Dental Therapy, 1993; No R1741. Available from: www.hpcsa.co.za. 


\section{new}

HELPS REBUILD

\& STRENGTHEN

YOUR ENAMEL

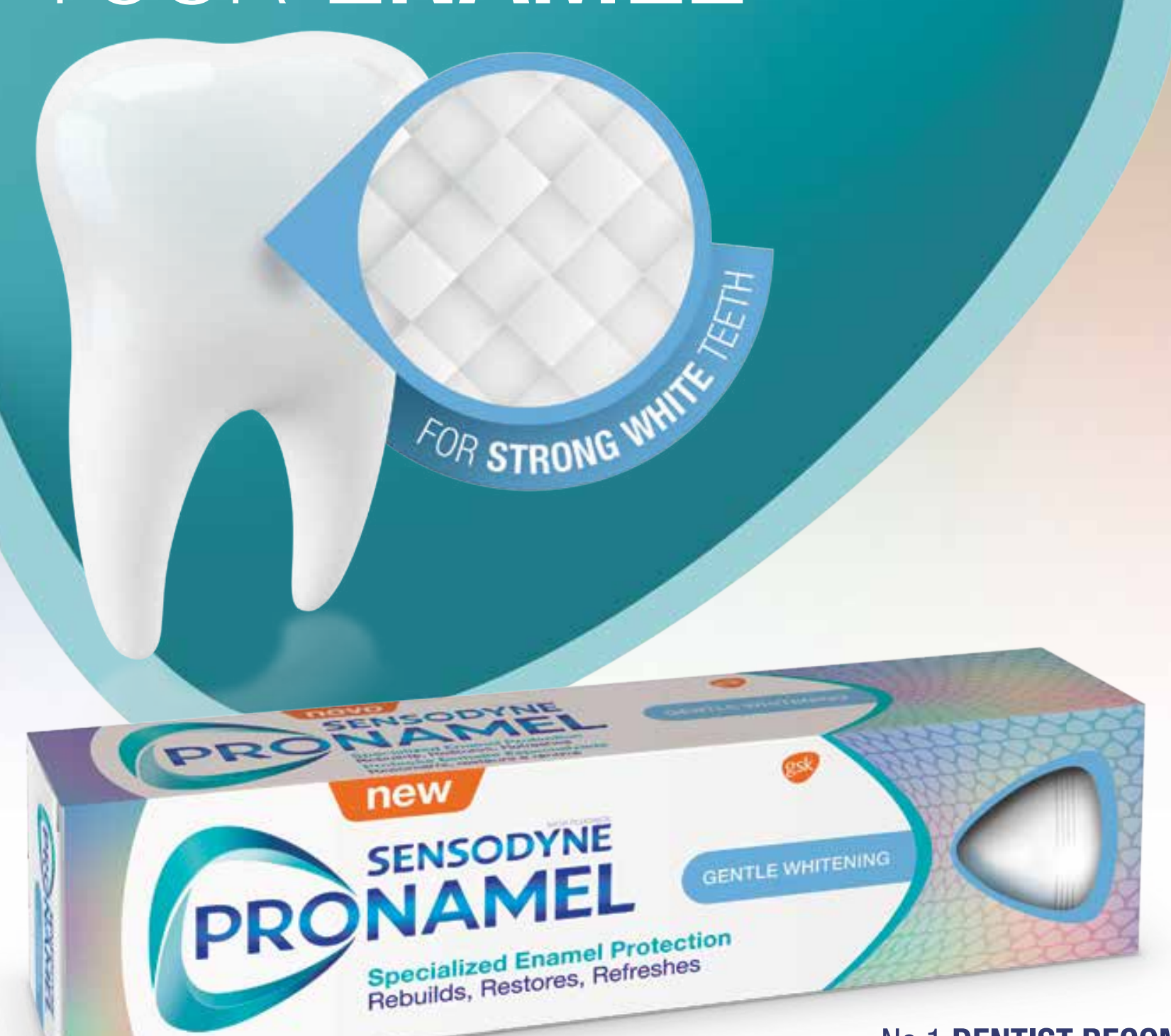

No.1 DENTIST RECOMMENDED

BRAND FOR SENSITIVE TEETH*

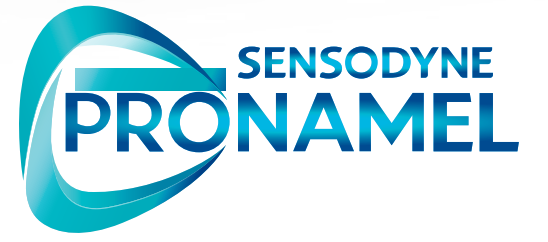

Specialized Enamel Protection
Rebuilds, Restores, Refreshes 